\title{
Caracterização de Solos de Pernambuco quanto à Supressividade a Pectobacterium carotovorum subsp. carotovorum
}

\author{
Indira del C.M. Alvarado ${ }^{1}$, Sami J. Michereff ${ }^{1}$, Rosa L.R. Mariano ${ }^{1}$, \\ Adriano M.F. Silva ${ }^{1} \&$ Clístenes W.A. Nascimento ${ }^{2}$
}

${ }^{1}$ Área de Fitossanidade, ${ }^{2}$ Área de Solos, Departamento de Agronomia, Universidade Federal Rural de Pernambuco, CEP 52171-900, Recife, PE, Brasil, e-mail: rmariano@truenet.com.br

Autor para correspondência: Rosa L.R. Mariano

ALVARADO, I.C.M., MICHEREFF, S.J., MARIANO, R.L.R., SILVA, A.M.F. \& NASCIMENTO, C.W.A. Caracterização de solos de Pernambuco quanto à supressividade a Pectobacterium carotovorum subsp. carotovorum. Fitopatologia Brasileira 32:222-228. 2007.

\section{RESUMO}

A podridão-mole causada por Pectobacterium carotovorum subsp. carotovorum (Pcc) é fator limitante para o cultivo de olerícolas no estado de Pernambuco. As características do solo e os fatores ambientais podem influenciar a população de Pcc e o desenvolvimento da doença. Este trabalho objetivou avaliar a taxa de extinção da população de Pcc em 24 amostras de solos de Pernambuco e analisar as características físicas, químicas e microbiológicas dos solos associadas com a supressividade ou conducividade ao patógeno. No estudo da influência dos solos na população de Pcc, utilizou-se mutante resistente a rifampicina (Pcc127 Rif), sendo calculada a taxa de extinção relativa da população (TERP) que variou de 0,0547 a 0,6327 log (UFC)/dia. Seis solos mostraram-se supressivos a Pcc127 Rif enquanto cinco evidenciaram conducividade. Os grupos de solos baseados na TERP de Pcc127 Rif não apresentaram relação com os municípios de coleta, tipos de coberturas do solo na época da coleta ou classes texturais dos solos. Considerando-se todos os solos, não foram constatadas correlações significativas $(\mathrm{P} \leq 0,05)$ entre a TERP de Pcc127 Rif e as características químicas, físicas e microbiológicas dos solos. Nos seis solos mais supressivos, a TERP de Pcc127 $7^{\text {Rif }}$ se correlacionou significativamente com a densidade aparente do solo $(\mathrm{r}=$ 0,76), populações de bactérias totais $(\mathrm{r}=0,82)$ e Bacillus $\mathrm{sp} .(\mathrm{r}=0,80)$. A população de Bacillus sp. se correlacionou com a densidade aparente, mas não com a população de bactérias totais. Nos cinco solos que se apresentaram mais conducivos houve correlação entre a TERP de Pcc127 Rif e a população de Bacillus sp. $(\mathrm{r}=-0,86)$.

Palavras-chave adicionais: podridão-mole, solos supressivos, solos conducivos, ecologia.

\begin{abstract}
Characterization of soils from Pernambuco State related to suppressiveness for Pectobacterium carotovorum subsp. carotovorum

The soft-rot caused by P. carotovorum subsp. carotovorum (Pcc) is a limiting factor for vegetable harvests in Pernambuco State. Soil characteristics and environmental factors may influence Pcc population and development of soft-rot. This work aimed to evaluate the extinction rate of Pcc population in 24 soil samples of Pernambuco and analyze physical, chemical and microbiological soil characteristics associated with suppressiveness or conduciveness for the pathogen. In the study of soil influence on Pcc population a rifampicin-resistant mutant was utilized (Pcc127 Rif). The extinction rate of population (TERP) was calculated and ranged from 0.0547 to $0.6327 \log (\mathrm{CFU}) / \mathrm{d}$. Six soils showed suppressiveness for Pcc127 $7^{\text {Rif }}$ while five presented conduciveness. The soil groups based on the TERP of Pcc127 $7^{\text {Rif }}$ did not correlate with municipalities, types of vegetation cover at the sampling time or soil textural classes. Considering all soils, there were no significant correlations $(\mathrm{P} \leq 0.05)$ among TERP of $\mathrm{Pcc} 127^{\text {Rif }}$ and chemical, physical and microbiological characteristics of soils. Considering the six most suppressive soils, the TERP of Pcc127 $7^{\text {Rif }}$ significantly correlated with apparent soil density $(\mathrm{r}=0.76)$, total bacterium population $(\mathrm{r}=0.82)$ and Bacillus sp. $(\mathrm{r}=0.80)$. The Bacillus sp. population correlated with apparent density, but not with total bacterium population. Considering the five most conducive soils there was correlation between TERP of Pcc127 Rif and Bacillus sp. population $(\mathrm{r}=-0.86)$.
\end{abstract}

Additional keywords: soft rot, suppressive soils, conducive soils, ecology.

\section{INTRODUÇÃO}

Pectobacterium carotovorum subsp. carotovorum (Pcc) (Jones) Hauben et al. é uma enterobactéria que causa podridão-mole em ampla gama de plantas hospedeiras em

Parte da Tese de Doutorado do primeiro autor. Universidade Federal Rural de Pernambuco. Recife PE. 2006. todo o mundo (Pérombelon \& Kelman, 1980). A podridãomole é uma doença de importância econômica em diversas culturas, incluindo couve-chinesa (Brassica pekinensis L.) (Kikumoto, 1980), alface, beterraba, couve, pimentão, repolho e tomate (Pérombelon, 2002). Em levantamentos realizados no estado de Pernambuco em 2004, a podridãomole teve prevalência de $100 \%$ em cultivos de couvechinesa e de 45,2\% em cultivos de alface, evidenciando a importância da doença para essas olerícolas (Silva, 2005). 
O controle da podridão-mole é muito difícil, uma vez que $P$. carotovorum subsp. carotovorum sobrevive em restos culturais infectados, na rizosfera de plantas cultivadas ou invasoras, na água, no solo, como epifítica na filosfera de plantas hospedeiras ou invasoras e em insetos (Kikumoto, 1980; Pérombelon \& Kelman, 1980). As características do solo, juntamente com os fatores ambientais, podem influenciar na população de Pcc, acelerando ou retardando o desenvolvimento da podridão-mole (Pérombelon \& Kelman, 1980).

O fenômeno de alguns solos prevenirem naturalmente o estabelecimento de patógenos ou inibirem as suas atividades patogênicas é denominado supressividade e estes solos de supressivos, o oposto de solos conducivos. A distinção entre supressão à doença e supressão ao patógeno deve ser efetuada, sendo esta última a habilidade de um solo em reduzir a densidade de inóculo do patógeno e sua atividade saprofítica, enquanto a primeira a capacidade do solo de reduzir a intensidade da doença, mesmo com alta densidade de inóculo e capacidade de sobrevivência do patógeno (Cook \& Baker, 1983).

A supressividade de solos é uma característica desejável, pois possibilita o controle de doenças com maior eficiência e menores danos ambientais. Fatores que determinam a supressividade devem ser estudados visando à utilização dessas informações na indução da supressividade em solos conducivos. Interações complexas entre fatores abióticos e bióticos do solo podem conduzir à supressividade, motivo pelo qual, propriedades do solo como textura e tipo de argila, densidade de partículas e densidade aparente, teores de nitrogênio $(\mathrm{N})$ total, fósforo $(\mathrm{P})$, potássio $(\mathrm{K})$, carbono $(\mathrm{C})$, alumínio $(\mathrm{Al})$, cálcio $(\mathrm{Ca})$, magnésio $(\mathrm{Mg})$, sódio $(\mathrm{Na})$ e matéria orgânica (MO), relação $\mathrm{C} / \mathrm{N}$, condutividade elétrica e potencial hidrogeniônico $(\mathrm{pH})$, assim como densidade, biomassa e atividade microbiana, dentre outras, podem ser usadas como indicadoras da supressividade (Hornby, 1983; Chellemi \& Porter, 2001; Bettiol \& Ghini, 2005).

Como não existem estudos sobre a supressividade de solos a populações de Pcc em regiões tropicais, este trabalho teve como objetivos avaliar a taxa de extinção da população desse patógeno em solos de Pernambuco e analisar as características físicas, químicas e biológicas dos solos associadas com a supressividade ou conducividade ao patógeno.

\section{MATERIAL E MÉTODOS}

\section{Coletas das amostras de solo}

Foram coletadas amostras de solo em 24 áreas selecionadas ao acaso, localizadas no Estado de Pernambuco (Tabela 1). As coletas foram efetuadas durante os meses de maio e junho de 2005 , sendo que em cada área foram removidas, aleatoriamente, seis subamostras de $5 \mathrm{~kg}$ de solo a uma profundidade de 0-20 $\mathrm{cm}$, totalizando $30 \mathrm{~kg}$ de solo/área. Em cada área foram obtidas informações adicionais sobre a cultura plantada e a localização geográfica foi referenciada pelo Sistema de Posicionamento Global (GPS 48 Personal Navigator, Garmin International, Olathe KS, USA).

\section{Análises microbiológicas dos solos}

Para as análises microbiológicas, as amostras de solo foram processadas dentro de 72 horas após a coleta. De cada amostra foram retiradas 10 sub-amostras de $10 \mathrm{~g} \mathrm{e}$ homogeneizadas, sendo efetuadas diluições em série (1:10) e plaqueamento nos meios BDA (batata-dextrose-ágar), com e sem adição de $250 \mathrm{ppm}$ de tetraciclina, para isolamento de fungos totais e bactérias totais, respectivamente; e meio B de King (KB) para isolamento de Pseudomonas sp. fluorescentes. No isolamento de Bacillus sp. as diluições foram submetidas a banho-maria de $80{ }^{\circ} \mathrm{C}$ por $20 \mathrm{~min}$, com posterior distribuição em meio $\mathrm{BDA}$, sem adição de antibiótico. As culturas foram incubadas a $25 \pm 2{ }^{\circ} \mathrm{C}$, sob alternância luminosa (12 h claro/12 h escuro), em incubadoras tipo B.O.D. (Biochemistry Oxigen Demand). As populações bacterianas foram avaliadas após $48 \mathrm{~h}$ de incubação, enquanto os fungos foram avaliados após cinco dias. Cada população resultou do número médio de colônias em seis placas, sendo expressas em unidades formadoras de colônias por grama de solo (UFC/g).

\section{Análises físicas e químicas dos solos}

As amostras de solo para as análises físicas e químicas foram secas em ambiente coberto durante 10 dias e depois peneiradas para retirada de resíduos, sendo mantidas em sacos de nylon até o processamento. As amostras foram submetidas às análises da densidade aparente $\left(\mathrm{g} / \mathrm{cm}^{3}\right)$, densidade da partícula $\left(\mathrm{g} / \mathrm{cm}^{3}\right)$, porcentagem de areia, argila e silte, $\mathrm{pH}$ em água, $\mathrm{K}, \mathrm{Ca}$, $\mathrm{Mg}$, Na e $\mathrm{Al}$ trocáveis $\left(\mathrm{cmolc} / \mathrm{dm}^{3}\right)$, acidez potencial $(\mathrm{H}+\mathrm{Al})$ $\left(\mathrm{cmolc} / \mathrm{dm}^{3}\right), C$ orgânico $(\mathrm{g} / \mathrm{kg})$, soma de bases (SB), saturação de bases (v) e saturação por alumínio (m) (EMBRAPA, 1997).

\section{Influência dos solos na população de Pectobacterium carotovorum subsp. carotovorum}

Foram utilizadas as 24 amostras de solo e um isolado de P. carotovorum subsp. carotovorum (Pcc127 $7^{\mathrm{Ri}}$ ), mutante espontâneo resistente ao antibiótico rifampicina (100 ppm), obtido a partir do isolado selvagem Pcc127, proveniente de planta de couve-chinesa com sintomas típicos de podridãomole. O isolado Pcc127 $7^{\text {Rif }}$ apresentou comportamento similar ao isolado selvagem em relação ao crescimento em meio líquido NYD (caldo nutritivo-extrato de levedura-dextrose) e patogenicidade a plantas de couve-chinesa (cv. Komachi).

No preparo do inóculo de Pcc127 Rif, a partir de cultura com 36-48 h em meio NYDA (ágar nutritivo-extrato de levedura-dextrose) foi preparada suspensão bacteriana em água destilada esterilizada, com concentração de $1 \times 10^{9}$ UFC/ $\mathrm{mL}$, ajustada em fotocolorímetro $\left(\mathrm{A}_{570}=0,36\right)$ de acordo com equação previamente estabelecida. Os diferentes solos foram colocados em caixas tipo Gerbox ${ }^{\circledR}$ (200 g de solo/caixa) e a cada caixa foram adicionados $50 \mathrm{~mL}$ de suspensão bacteriana de Pcc127 ${ }^{\text {Rif }}$, homogeneizando-se com auxílio de bastão de vidro. As caixas foram incubadas em B.O.D. a $25 \pm 2{ }^{\circ} \mathrm{C}$. 
TABELA 1 - Influência de solos do Estado de Pernambuco na taxa de extinção da população (TERP) de Pectobacterium carotovorum subsp. carotovorum

\begin{tabular}{llllc}
\hline \hline Código do solo & \multicolumn{1}{c}{ Local (município) } & \multicolumn{1}{c}{ Cobertura $^{1}$} & \multicolumn{1}{c}{ Textura } & TERP \\
\hline CF-1 & Camocim de São Félix & couve-chinesa & Franco arenoso & $0,6327 \mathrm{a}^{3}$ \\
SA-1 & Sairé & milho & Franco argilo arenoso & $0,5439 \mathrm{~b}$ \\
BG-1 & Barra de Guabiraba & sem plantio & Franco argilo arenoso & $0,4011 \mathrm{c}$ \\
CO-1 & Condado & cana-de-açúcar & Argila & $0,3682 \mathrm{c}$ \\
GR-1 & Gravatá & couve-chinesa & Franco arenoso & $0,3357 \mathrm{c}$ \\
GR-2 & Gravatá & pimentão & Franco arenoso & $0,3145 \mathrm{c}$ \\
CF-2 & Camocim de São Félix & couve-chinesa & Franco argilo arenoso & $0,2801 \mathrm{~d}$ \\
AL-1 & Abreu e Lima & cana-de-açúcar & Areia franca & $0,2315 \mathrm{~d}$ \\
CG-1 & Chã Grande & brócoli & Franco arenoso & $0,2301 \mathrm{~d}$ \\
CF-3 & Camocim de São Félix & couve-chinesa & Franco argilo arenoso & $0,2004 \mathrm{~d}$ \\
BO-1 & Bonito & mata & Argila & $0,2003 \mathrm{~d}$ \\
SJ-1 & São Joaquim do Monte & pimentão & Franco argilo arenoso & $0,1992 \mathrm{~d}$ \\
CF-4 & Camocim de São Félix & pimentão & Franco argilo aren oso & $0,1722 \mathrm{~d}$ \\
SJ-2 & São Joaquim do Monte & pimentão & Franco arenoso & $0,1667 \mathrm{~d}$ \\
CG-2 & Chã Grande & pimentão & Franco arenoso & $0,1519 \mathrm{e}$ \\
CF-5 & Camocim de São Félix & couve-chinesa & Franco argilo arenoso & $0,1483 \mathrm{e}$ \\
GR-3 & Gravatá & couve-chinesa & Franco argilo arenoso & $0,1397 \mathrm{e}$ \\
CF-6 & Camocim de São Félix & couve-chinesa & Franco argilo arenoso & $0,1238 \mathrm{e}$ \\
AN-1 & Aliança & cana-de-açúcar & Franco arenoso & $0,1121 \mathrm{e}$ \\
IG-1 & Igarassu & inhame & Franco arenoso & $0,0914 \mathrm{f}$ \\
CO-2 & Condado & cana-de-açúcar & Franco arenoso & $0,0806 \mathrm{f}$ \\
CF-7 & Camocim de São Félix & couve-chinesa & Franco argilo arenoso & $0,0799 \mathrm{f}$ \\
CF-8 & Camocim de São Félix & couve-chinesa & Franco arenoso & $0,0718 \mathrm{f}$ \\
CF-9 & Camocim de São Félix & couve-chinesa & Franco arenoso & $0,0547 \mathrm{f}$ \\
\hline C.V. $(\%)$ & & & & 10,34 \\
\hline
\end{tabular}

${ }^{1}$ Tipo de cobertura do solo na época da coleta.

${ }^{2}$ Taxa de extinção relativa da população de $P$. carotovorum subsp. carotovorum no solo [log (UFC)/dia], calculada conforme Kocks et al. (1998).

${ }^{3}$ Médias de quatro repetições. Médias seguidas pela mesma letra não diferem significativamente entre si pelo teste de Scott-Knott $(\mathrm{P}=0,05)$

Para avaliação dos níveis populacionais de Pcc127 Rif, foram processadas semanalmente amostras de $0,5 \mathrm{~g}$ de solo, até que em duas amostragens consecutivas, a bactéria não fosse detectada. As amostras foram colocadas em tubos contendo $4,5 \mathrm{~mL}$ de água destilada esterilizada, os quais foram agitados em agitador tipo vórtex, na potência 10 durante $30 \mathrm{~s}$. Em condições assépticas, foram realizadas diluições até $10^{-3}$, plaqueando-se $0,1 \mathrm{~mL}$ de cada suspensão em meio NYDA contendo 100 ppm de rifampicina e $250 \mathrm{ppm}$ do fungicida clorotalonil ( $\mathrm{NYDA}^{\text {Rif }}{ }^{\mathrm{Clt}}$ ). O fungicida foi selecionado previamente como inibidor eficiente dos contaminantes fúngicos existentes nos solos. As placas foram incubadas por $36 \mathrm{~h}$ a $28 \pm 2{ }^{\circ} \mathrm{C}$, quando foi realizada a contagem do número de colônias, determinando-se o número de UFC/g de solo. Em cada amostra de solo, os dados populacionais de Pcc127 $7^{\text {Rif }}$ foram utilizados para o cálculo da taxa de extinção relativa da população $(T E R P)$, pela expressão TERP $=-\left(\left(\log \mathrm{Y}_{\mathrm{f}}\right.\right.$ $\left.\left.-\log \mathrm{Y}_{0}\right) /\left(\mathrm{T}_{\mathrm{f}}-\mathrm{T}_{0}\right)\right)$, onde $\mathrm{Y}_{0}$ é a população aos sete dias após a infestação do solo, $\mathrm{Y}_{\mathrm{f}}$ a população na última avaliação antes de zerar, $\mathrm{T}_{\mathrm{f}} \mathrm{o}$ tempo (em dias) da última avaliação sem zerar e $\mathrm{T}_{0} \mathrm{o}$ tempo da primeira avaliação (dia =7) (Kocks et al., 1998).

$\mathrm{O}$ delineamento experimental foi inteiramente casualizado, com cinco repetições, sendo cada repetição constituída por uma caixa Gerbox ${ }^{\circledR}$. Os dados foram submetidos à análise de variância e as médias comparadas pelo teste de Scott-Knott, ao nível de $5 \%$ de probabilidade.

\section{Caracterização da supressividade ou conducividade dos solos a Pectobacterium carotovororum subsp. carotovorum}

Para caracterizar os possíveis fatores envolvidos na supressividade ou conducividade dos solos a Pcc127Rif, foram efetuadas comparações dos valores médios da TERP com as demais variáveis avaliadas em cada solo, pela análise de correlação de Pearson, ao nível de $5 \%$ de probabilidade. Essas comparações foram realizadas em três etapas: na primeira foram comparados todos os 24 solos, na segunda os seis solos com maiores níveis de supressividade e na terceira os cinco solos com maiores níveis de conducividade, conforme os resultados da análise de Scott-Knott. Todas as análises estatísticas foram realizadas com o auxílio do programa SAEG ${ }^{\circledR} 9.0$ (Sistema deAnálises Estatísticas e Genéticas, Universidade Federal de Viçosa, 2005).

\section{RESULTADOS E DISCUSSÃO}

As taxas de extinção relativa das populações (TERP) de P. carotovorum subsp. carotovorum (Pcc127 ${ }^{\mathrm{Rif}}$ ) nos solos 
de Pernambuco variaram de $0,0547 \log$ (UFC)/dia a 0,6327 $\log (\mathrm{UFC}) /$ dia, sendo formados seis diferentes grupos de solos pelo teste de agrupamento de Scott-Knott $(\mathrm{P}=0,05)$ (Tabela 1). As maiores TERP foram observadas nos solos CF-1, SA-1, BG-1, CO-1, GR-1 e GR-2, enquanto as menores taxas foram constatadas nos solos IG-1, CO-2, CF-7, CF-8 e CF-9 (Tabela 1).

A diferença na TERP de Pcc $127^{\text {Rif }}$ em vários solos com a mesma densidade inicial de inóculo, como verificado no presente estudo, indica a variabilidade do potencial de inóculo em diferentes tipos de solo, entendendo-se como potencial de inóculo a energia de crescimento do organismo patogênico que está disponível para a infecção do hospedeiro, resultante da densidade de inóculo ou número de propágulos, da energia exógena e endógena dos propágulos por unidade, da virulência dos propágulos e dos fatores ambientais, bióticos e abióticos, determinantes da atividade do inóculo (Lockwood, 1988). Essa variabilidade existente entre os solos permite, segundo Huber \& Schneider (1982), classificá-los em supressivos ou conducivos. Nesse contexto, os solos CF-1, SA-1, BG-1, CO-1, GR-1 e GR-2 mostraramse supressivos a Pcc $127^{\text {Rif }}$, enquanto IG-1, CO-2, CF-7, CF8 e CF-9 evidenciaram conducividade. A maioria dos solos apresentou comportamento intermediário em relação a esses extremos.

A formação dos grupos de solos baseada na TERP de Pcc127 $7^{\text {Rif }}$ não apresentou relação com os locais (municípios) de coleta das amostras dos solos, tipos de coberturas do solo na época da coleta ou classes texturais dos solos. A ausência de associação entre histórico de cultivo e populações de Pcc127 Rif, como constatado no presente estudo, foi previamente relatada por Pérombelon \& Hyman (1989), baseado em estudo realizado na Escócia no período de 1981 a 1983, envolvendo três campos previamente cultivados com batata. Na maioria das vezes é impossível estabelecer uma relação entre o nível populacional de Pcc no solo e o início da podridão-mole em couve-chinesa, tendo em vista a grande influência da presença de ferimentos no pecíolo do hospedeiro, bem como da umidade e da temperatura do solo (Togashi \& Sakamoto, 1966). Em geral, a bactéria existe no solo em baixos níveis populacionais, menos que $10^{2} \mathrm{UFC} / \mathrm{g}$ solo, mas se multiplica rapidamente no solo em contato com o pecíolo ou solo rizosférico do hospedeiro (Togashi, 1972; Mew et al., 1976). Portanto, como Pcc possui um tempo de geração curto, uma pequena quantidade de inóculo primário sobrevivente no solo pode produzir rapidamente uma epidemia na presença de condições favoráveis (Schuster \& Coyne, 1974).

Na análise dos possíveis indicadores da supressividade ou conducividade dos solos à população de $\operatorname{Pcc} 127^{\mathrm{Rif}}$, não foram constadas correlações significativas $(\mathrm{P}=0,05)$ entre a TERP e as características químicas, físicas e microbiológicas quando todos os solos foram considerados (Tabela 2). Esse resultado indica que não é possível destacar uma ou um conjunto de características responsáveis pela supressividade ou conducividade em todos os solos. Portanto, os fatores responsáveis pela supressividade em determinado solo podem não exercer o mesmo papel em outros, confirmando as observações de Arshad \& Martin (2002) sobre a complexidade das interações entre as diferentes propriedades físicas, químicas e microbiológicas do solo, o que torna difícil a identificação de indicadores de supressividade do solo que possam ser utilizados em diferentes situações, e reflete, segundo Höper \& Alabouvette (1996), na dificuldade freqüentemente encontrada para distinção entre fatores primários e secundários responsáveis pela supressividade a doenças e/ou patógenos.

Quando considerados somente os seis solos mais supressivos, a TERP de Pcc127 $7^{\text {Rif }}$ se correlacionou significativamente $(\mathrm{P} \leq 0,05)$ com a densidade aparente do solo $(\mathrm{r}=0,76)$, com as populações de bactérias totais $(\mathrm{r}=$ $0,82)$ e Bacillus sp. $(\mathrm{r}=0,80)$. A população de Bacillus sp. se correlacionou com a densidade aparente $(\mathrm{r}=0,96)$, mas não com a população de bactérias totais $(\mathrm{r}=0,71)$, o que pode ser conseqüência da utilização do mesmo método (plaqueamento em BDA e incubação a $25 \pm 2{ }^{\circ} \mathrm{C}$ sob alternância luminosa, durante 48 horas) para a quantificação das duas populações. Vieira \& Nahas (2000) observaram que as maiores contagens

TABELA 2 - Correlações entre taxa de extinção relativa da população de Pectobacterium carotovorum subsp. carotovorum (TERP) e variáveis físicas, químicas e microbiológicas dos solos de Pernambuco, considerando todos os solos analisados (geral) e somente os classificados como supressivos ou conducivos

\begin{tabular}{|c|c|c|c|}
\hline \multirow{2}{*}{ Variáveis ${ }^{1}$} & \multicolumn{3}{|c|}{ Coeficiente de correlação $^{1}$} \\
\hline & Geral & Supressivos & Conducivos \\
\hline Areia (Ar) & $-0,29$ & $-0,03$ & $-0,26$ \\
\hline Argila (Ag) & 0,14 & $-0,05$ & $-0,07$ \\
\hline Silte (Si) & 0,46 & 0,14 & 0,74 \\
\hline Reação Silte/Argila (Si/Ag) & 0,20 & 0,14 & 0,56 \\
\hline Dens idade aparente (DA) & 0,08 & $0,76^{*}$ & 0,50 \\
\hline Densidade de partículas (DP) & 0,05 & 0,68 & $-0,40$ \\
\hline $\mathrm{pH}\left(\mathrm{H}_{2} \mathrm{O}\right)$ & $-0,06$ & $-0,23$ & 0,65 \\
\hline Potássio (K) & 0,02 & $-0,08$ & 0,58 \\
\hline Sódio (Na) & 0,12 & 0,47 & $-0,05$ \\
\hline Cálcio (Ca) & 0,01 & $-0,01$ & 0,39 \\
\hline Cálcio + Magnésio $(\mathrm{Ca}+\mathrm{Mg})$ & 0,11 & $-0,06$ & 0,52 \\
\hline Alumínio (Al) & 0,20 & $-0,25$ & $-0,10$ \\
\hline Carbono orgânico (CO) & $-0,02$ & $-0,03$ & 0,65 \\
\hline Acidez potencial $(\mathrm{H}+\mathrm{Al})$ & 0,04 & 0,35 & $-0,31$ \\
\hline Soma de bases (SB) & 0,11 & $-0,05$ & 0,54 \\
\hline Saturação de bases (v) & 0,06 & $-0,17$ & 0,43 \\
\hline Saturação por alumínio (m) & 0,16 & $-0,24$ & $-0,08$ \\
\hline Relação $\mathrm{Ca} / \mathrm{Mg}(\mathrm{Ca} / \mathrm{Mg})$ & $-0,10$ & 0,09 & $-0,40$ \\
\hline Relação $\mathrm{Ca} / \mathrm{K}(\mathrm{Ca} / \mathrm{K})$ & 0,10 & $-0,15$ & $-0,20$ \\
\hline Bacterias totais (BT) & 0,07 & $0,82 *$ & 0,35 \\
\hline Pseudomonas fluorescentes (PF) & $-0,09$ & $-0,02$ & 0,58 \\
\hline Bacillus sp. (BC) & 0,03 & $0,80^{*}$ & $-0,86^{*}$ \\
\hline Fungos totais $(\mathrm{FT})$ & 0,26 & $-0,16$ & 0,17 \\
\hline
\end{tabular}

${ }^{1}$ Coeficientes de correlação de Pearson seguidos por asterisco são significativos a $\mathrm{P} \leq 0,05$. 
de bactérias totais e de Bacillus sp. provenientes de solos foram obtidas em diferentes meios de cultura, temperaturas e períodos de incubação. Uma maior população de bactérias totais no solo, não significa necessariamente maior ou menor número de Bacillus sp., pois existem várias populações de outros microrganismos que podem impedir uma correlação. Nahas et al. (1997) estudando a atividade microbiana em solo após aplicação de gesso agrícola também não observaram correlação entre aumento de número de bactérias totais e de Bacillus sp. Nos cinco solos mais conducivos, houve correlação negativa entre a TERP de Pcc127 ${ }^{\text {Rif }}$ e a população de Bacillus sp. $(\mathrm{r}=-0,86)$. Por outro lado, as características químicas do solo não se correlacionaram com a TERP nas diferentes combinações de solos (Tabela 2).

A densidade populacional e a sobrevivência de microrganismos no solo dependem de vários fatores, destacando-se a capacidade de produzir estruturas de sobrevivência, os fatores que controlam ou afetam a produção destas estruturas, as condições que afetam a sobrevivência destas estruturas, a diversidade fisiológica, a eficiência na utilização de substratos, os números de hospedeiros principais e alternativos, a competitividade e capacidade de saprofitismo, as estratégias de sobrevivência e a suscetibilidade à microbiostase e antibióticos presentes no solo (Siqueira \& Franco, 1988).

A disponibilidade de nutrientes e os níveis de $\mathrm{pH}$ no solo parecem não ter afetado as populações de Pcc $127^{\mathrm{Rif}}$ nesse estudo. No entanto, já foi constatado que valores elevados de $\mathrm{pH}, \mathrm{P}, \mathrm{Ca}$ e $\mathrm{Mg}$ propiciam aumentos significativos nos níveis populacionais desta bactéria no solo (Kikumoto, 1980; Pérombelon \& Hyman, 1989; Armon et al., 1995). Por outro lado, a podridão-mole em couve-chinesa foi eficientemente controlada em campo pela fertilização do solo com hidróxido de cálcio (Kim \& Yeoung, 2004).

A importância das propriedades físicas do solo na supressividade de fungos fitopatogênicos habitantes desse ambiente foi destacada por Höper \& Alabouvette (1996). A densidade aparente do solo é determinada pela quantidade de espaços porosos e sólidos do solo, sendo que solos com elevada proporção de espaços porosos em relação aos sólidos têm densidades menores do que outros mais compactos e com menos espaços porosos (Brady, 1989). Como o nível de porosidade pode exercer efeito seletivo sobre a capacidade de colonização por determinados microrganismos (Siqueira \& Franco, 1988), a correlação positiva entre densidade aparente do solo e TERP de Pcc127 Rif pode ser conseqüência do nível de porosidade, uma vez que as populações de bactérias são geralmente desfavorecidas pela reduzida porosidade do solo $\mathrm{e}$, consequentemente, elevada densidade aparente.

Os solos constituem um sistema dinâmico, onde complexas interações entre as propriedades físicas, químicas e biológicas, se integram continuamente, influenciando e diversificando a microbiota (Siqueira \& Franco, 1988). A elevada correlação observada entre supressividade do solo a Pcc127 $7^{\text {Rif }}$ e as populações de bactérias totais era esperada, pois as populações de pectobactérias declinam muito rapidamente em solos, no campo, dependendo da população bacteriana no mesmo, além de outros fatores (Mew et al., 1976; Pérombelon \& Kelman, 1980). A redução da população de Pcc127 $7^{\text {Rif }}$ no solo pode ser atribuída à competição com bactérias nativas que utilizam os nutrientes mais eficientemente, a exemplo do constatado por Armon et al. (1995), mas o mecanismo de antibiose também pode estar envolvido, pois Kikumoto (2000) destacou que a diferença na habilidade de isolados desta bactéria sobreviverem no solo estava relacionada à sensibilidade a bacteriocinas. Este autor demonstrou o potencial do controle biológico da podridãomole em couve-chinesa, baseado na utilização de isolados avirulentos de Pcc produtores de bacteriocinas. Entretanto nenhum método efetivo de controle foi estabelecido.

Os gêneros de bactérias mais comumente encontrados nos solos com capacidade antagonística a fitopatógenos são Pseudomonas sp. e Bacillus sp. (Weller et al., 2002; Bettiol \& Ghini, 2005). Nesse estudo, as populações de Pseudomonas fluorescentes não se correlacionaram com a TERP de Pcc127 $7^{\text {Rif }}$ em nenhuma das situações analisadas, embora Mew et al. (1976) tenham observado que a presença de Pseudomonas fluorescentes no solo influenciou significativamente na redução da severidade da podridãomole em couve-chinesa. Por outro lado, a influência das populações de Bacillus sp. na supressividade a Pcc127 ${ }^{\text {Rif }}$ verificada no presente estudo constitui um aspecto relevante, pois segundo Mazzola (2004), a implementação efetiva de estratégias de manejo ou estímulo à comunidade microbiana antagonista do solo para a supressão de fitopatógenos habitantes desse ambiente requer inicialmente a identificação dos componentes biológicos envolvidos na supressividade e depois o monitoramento do impacto das práticas de manejo na abundância e atividade dessa população microbiana benéfica.

A influência de bactérias formadoras de endosporos na sobrevivência de $P$. carotovorum foi estudada por Kikumoto (1980), que verificou o decréscimo rápido na população do patógeno com o aumento das populações de bactérias formadoras de endosporos. Espécies de Bacillus, incluindo B. thuringiensis Berliner, B. subtilis (Ehrenberg) Cohn e B. cereus Frankland \& Frankland destacaram-se como importantes agentes de biocontrole de fitopatógenos habitantes do solo (Emmert \& Handelsman, 1999). Essas bactérias são produtoras de antibióticos, além de enzimas que degradam moléculas envolvidas no sinal de "quorum sensing" de muitas bactérias (Garbeva et al., 2004), a exemplo de $B$. thuringiensis no biocontrole de $P$. carotovorum (Dong et al., 2004). Mesmo considerando todos esses aspectos, um entendimento completo dos fatores biológicos responsáveis pela supressividade de um solo a um determinado patógeno ou doença requer um conhecimento aprofundado da identidade, freqüência relativa e atividade biológica das diversas populações microbianas que habitam a rizosfera. Além disso, o balanço microbiano e a eficiência de um antagonista são dependentes das características físico-químicas do solo, sendo difícil separar os fatores 
envolvidos na supressividade (Weller et al., 2002), o que ficou evidente no presente estudo com a constatação de correlação significativa entre a população de Bacillus sp. e a densidade aparente do solo.

Um aspecto a ser considerado na dificuldade da caracterização dos possíveis mecanismos envolvidos na supressividade dos solos de Pernambuco à população de Pcc127 Rif é a metodologia empregada, uma vez que foram utilizados indicadores tradicionais de supressividade (Hornby, 1983; Chellemi \& Porter, 2001). De acordo com Van Bruggen \& Semenov (1999), os resultados obtidos utilizando indicadores tradicionais são muito difíceis de interpretar, motivo pelo qual sugeriram um procedimento alternativo, baseado na mensuração de respostas biológicas a distúrbios ou estresse, assumindo que um solo sadio é um solo estável com resistência ao estresse. A resposta ao estresse em termos de amplitude e resistência da comunidade microbiana poderia ser um melhor indicador universal para supressão à doença que qualquer outro fator físico, químico ou biológico, mensurado somente uma vez a longos intervalos de tempo. Portanto, novos estudos devem ser realizados para a caracterização dos mecanismos de supressividade ou conducividade dos solos de Pernambuco a Pcc, visando contribuir efetivamente para o manejo integrado da podridão-mole em couve-chinesa.

\section{AGRADECIMENTOS}

$\mathrm{O}$ primeiro autor agradece à concessão de bolsa de estudos oferecida pela CAPES. Os autores agradecem ao $\mathrm{CNPq}$ pela concessão de auxílio financeiro (Proc. 479.622/2004-3) e bolsa de produtividade a S.J. Michereff, R.L.R. Mariano e C.W.A. Nascimento.

\section{REFERÊNCIAS BIBLIOGRÁFICAS}

ARMON, R., DOSORETZ, C., YOIRISH, A., SHELEF, G. \& NEEMAN, I. Survival of the phytopathogen Erwinia carotovora subsp. carotovora in sterile and non-sterile soil, sand and their admixture. Journal of Applied Bacteriology 79:513-518. 1995.

ARSHAD, M.A. \& MARTIN, S. Identifying critical limits for soil quality indicators in agro-ecosystems. Agriculture, Ecosystems and Environment 88:153-160. 2002.

BETTIOL, W. \& GHINI, R. Solos supressivos. In: Michereff, F., Andrade, D.E.G.T. \& Menezes, M. (Eds.) Ecologia e Manejo de Patógenos Radiculares em Solos Tropicais. Recife PE. Imprensa Universitária da Universidade Federal Rural de Pernambuco. 2005. pp. 125-152.

BRADY, N.C. Natureza e Propriedade dos Solos. 7. ed. Rio de Janeiro RJ. Freitas Bastos. 1989.

CHELLEMI, D.O. \& PORTER, I.J. The role of plant pathology in understanding soil health and its application to productive agriculture. Australasian Plant Pathology 30:103-109. 2001.

COOK, R.J. \& BAKER, K.F. The Nature and Practice of Biological
Control of Plant Pathogens. Saint Paul MN. APS Press. 1983.

DONG, Y.H., ZHANG, X.F., XU, J.L. \& ZHANG, L.H. Insecticidal Bacillus thuringiensis silences Erwinia carotovora virulence by a new form of microbial antagonism, signal interference. Applied and Environmental Microbiology 70:954-960. 2004.

EMBRAPA. Manual de Métodos de Análises de Solo. 2. ed. Rio de Janeiro RJ. EMBRAPA-CNPS. 1997.

EMMERT, E.A.B. \& HANDELSMAN, J. Biocontrol of plant disease: a (Gram-) positive perspective. FEMS Microbiology Letters 171:1-9. 1999

GARBEVA, P., VAN VEEN, J.A. \& VAN ELSAS, J.D. Microbial diversity in soil: selection of microbial populations by plant and soil type and implications for disease suppressiveness. Annual Review of Phytopathology 42:243-270. 2004.

HÖPER, H. \& ALABOUVETTE, C. Importance of physical and chemical soil properties in the suppressiveness of soil to plant diseases. European Journal of Soil Biology 32:41-58. 1996.

HORNBY, D. Suppressive soils. Annual Review of Phytopathology 21:65-85. 1983.

HUBER, D.M. \& SCHNEIDER, R.W. The description and occurrence of suppressive soils. In: Schneider, R.W. (Ed.) Suppressive Soils and Plant Disease. Saint Paul MN. APS Press. 1982. pp. 1-7.

KIKUMOTO, T. Ecological aspects of soft rot bacteria. Report of the Institute for Agricultural Research, Tohoku University. v.31:1941. 1980.

KIKUMOTO, T. Ecology and biocontrol of soft rot of Chinese cabbage. Journal of General Plant Pathology 66:275-277. 2000.

KIM, B.S. \& YEOUNG, Y.R. Suppression of bacterial rot on Chinese cabbage by calcium fertilizer treatment. Research in Plant Disease 10:82-85. 2004.

KOCKS, C.G., RUISSEM, M.A., ZADOKS, J.C. \& DUIJKERS, M.G. Survival and extinction of Xanthomonas campestris pv. campestris in soil. European Journal of Plant Pathology 104:911923. 1998.

LOCKWOOD, J.L. Evolution of concepts associated with soilborne plant pathogens. Annual Review of Phytopathology 26:93-121. 1988.

MAZZOLA, M. Assessment and management of soil microbial community structure for disease suppression. Annual Review of Phytopathology 42:35-59. 2004.

MEW, T.W., HO, W.C. \& CHU, L. Infectivity and survival of softrot bacteria in Chinese cabbage. Phytopathology 66:1325-1327. 1976.

NAHAS, E., DELFINO, J.H. \& ASSIS, L.C. Atividade microbiana e propriedades bioquímicas do solo resultantes da aplicação de gesso agrícola na cultura do repolho. Scientia Agricola 54:160166. 1997.

PÉROMBELON, M.C.M. Potato diseases caused by soft rot Erwinias: overview of pathogenesis. Plant Pathology 51:1-12. 2002.

PÉROMBELON, M.C.M. \& HYMAN, L.J. Survival of soft rot Erwinia carotovora subsp. carotovora and Erwinia carotovora subsp. atroseptica in soil in Scotland. Journal of Applied Bacteriology 66:95-106. 1989. 
PÉROMBELON, M.C.M. \& KELMAN, A. Ecology of the soft rot Erwinias. Annual Review of Phytopathology 18:361-387. 1980.

SCHUSTER, M.L. \& COYNE, D.P. Survival mechanisms of phytopathogenic bacteria. Annual Review Phytopathology 12:199221. 1974.

SILVA, A.M.F. Levantamento da intensidade da podridão-mole da alface e couve-chinesa nas regiões da mata e agreste do estado de Pernambuco e determinação do tamanho das amostras para avaliação da incidência da doença. Dissertação de Mestrado. Recife PE. Universidade Federal Rural de Pernambuco. 2005.

SIQUEIRA, J.O. \& FRANCO, A.A. Biotecnologia do Solo - Fundamentos e Perspectivas. Brasília. Ministério da Educação - ABEAS. ESAL/FAEPE. 1988.

TOGASHI, J. Studies on the outbreak of the soft-rot disease of Chinese cabbage by Erwinia aroideae (Towns.) Holl. Report of the Institute for Agricultural Research. Tohoku University. v.23:17-52. 1972.

TOGASHI, J. \& SAKAMOTO, M. Studies on the outbreak of the soft-rot disease of Chinese cabbage. Report of the Institute for Agricultural Research, Tohoku University. v.17:17-26. 1966.

VAN BRUGGEN, A.H.C. \& SEMENOV, A.M. A new approach to the search for indicators of root disease suppression. Australasian Plant Pathology 28:4-10. 1999.

VIEIRA, F.C.S. \& NAHAS, E. Quantificação de bactérias totais e esporuladas no solo. Scientia Agricola 57: 539-545. 2000.

WELLER, D.M., RAAIJMAKERS, J.M., GARDENER, B.B.M. \& THOMASHOW, L.S. Microbial populations responsible for specific soil suppressiveness to plant pathogens. Annual Review of Phytopathology 40:309-348. 2002.

Recebido 21 Agosto 2006 - Aceito 12 Junho 2007- FB 6091 